\title{
Metaphyseal chondrodysplasia, Kaitila type
}

INSERM

\section{Source}

INSERM. (1999). Orphanet: an online rare disease and orphan drug data base.

Metaphyseal chondrodysplasia, Kaitila type. ORPHA:166038

Metaphyseal chondrodysplasia, Kaitila type is a rare multiple metaphyseal dysplasia

disease characterized by disproportionate short stature, short limbs and dig its,

tracheobronchial malacia and progressive thoracolumbar scoliosis. Radiographic imaging shows progression from marked metaphyseal dysplasia of tubular bones in childhood to short and broad bones with mild dysplasia of the joints in adulthood. There have been no further descriptions in the literature since 1982. 